\title{
Study of Mifepristone and Misoprostol Vs Misoprostol alone in mid trimester termination of pregnancy in tertiary care hospital
}

\author{
MahendraG. ${ }^{1}$, Vyshali. $\mathbf{R}^{2}$, VijayalakshmiS. ${ }^{3}$ \\ ${ }^{1}$ Dr. Mahendra. G., Associate Professor, ${ }^{2}$ Dr. Vyshali. R, Postgraduate, ${ }^{3}$ Dr. Vijayalakshmi S., Professor and HOD; all \\ authors are affiliated with Adichunchanagiri Institute of Medical Sciences, B.G. Nagara, Mandya, Karnataka, India.
}

Corresponding Author: Dr. Vyshali. R, Postgraduate Student from Adichunchanagiri Institute of Medical Sciences B.G Nagara Mandya, Karnataka. Email id: vyshaliramachandra5@gmail.com

\begin{abstract}
Background: Over the last decade there is an increase in number of second trimester pregnancy termination due to better prenatal screening. Medical methods, using combination of Mifepristone Misoprostol are increasing being used for midtrimester pregnancy termination. Objective: The present study was conducted with an aim toassess and comparatively evaluate the efficacy of Mifepristone with Misoprostol and Misoprostol alone for mid trimester termination of pregnancy. Methods and Material: A prospective study was conducted on 50 women who presented to us for termination of pregnancy in the mid trimester due to various reasons. These 50 women were divided into two groups of 25 each. In the study group 1 , Mifepristone $200 \mathrm{mg}$ was given 24 hours before intravaginalinsertion of $200 \mathrm{mcg}$ of Misoprostol followed by $200 \mathrm{mcg}$ every 6 hrs until abortion occurs. In the control group 2, only Misoprostol was inserted in the same dose regime. The results were analysed for Primary outcomes i.e. Rate of complete abortion, Induction to abortion interval and failure to achieve complete abortion. Result: Mean induction abortion interval from insertion of the first Misoprostol tablet was significantly shorter in the Mifepristone pre-treated [mean duration7hours] group as compared to Misoprostol alone group [mean duration 18hours]. The mean dose of misoprostol required was significantly less in the study group[around 400mcg] and complete abortion occurred in $100 \%$ of casesas compared to control group in whom the mean dose of Misoprostol required was more [around $1200 \mathrm{mcg}$ ], with $8 \%$ failure for which Hysterotomy was done. Conclusion: Pre-treatment with Mifepristone 24hr before intravaginal Misoprostol significantly improves induction abortion interval.
\end{abstract}

Keywords: Second trimester termination of pregnancy, Mifepristone, Misoprostol

\section{Introduction}

Mid trimester abortion is termination of pregnancy between 13-28 weeks gestation. Indian MTP law (Medical Termination of pregnancy law, 1972) permits abortion till 20 weeks period of gestation by a registered medical practitioner provided all pre-requisites are met [1].

Although the majority of abortions are performed in the first trimester, there is still a need for second trimester abortion because of delayed diagnosis of fetal anomalies, logistic and financial difficulties in obtaining abortion services, and failure to recognise an undesired pregnancy in first trimester, which all contribute to the continuing need for late abortions [2,3]. Mid trimester abortions constitute $10-15 \%$ of all abortion cases but are responsible for two-thirds of all major complications (WHO, 1997) [4]. The medical methods, especially prostaglandins, have good success rates and reasonable complication rates. So,

Manuscript received: $8^{\text {th }}$ June 2018

Reviewed: $18^{\text {th }}$ June 2018

Author Corrected: $26^{\text {th }}$ June 2018

Accepted for Publication: $30^{\text {th }}$ June 2018

Obsgyne Review: Journal of Obstetrics and Gynecology medical methods have become increasingly popular for mid-trimester abortions.Prostaglandins (PG E1, PGE2 and PG F2 $\alpha$ ) has been used for mid-trimester pregnancy termination in the last 20 years. When prostaglandin E1 analogs (gemeprost or Misoprostol) are used alone for second trimester MTP, the mean inductionabortion interval (IAI) can be as long as 12-16 hours [6,7].

Pre-treatment with an antiprogesterone (mifepristone) prior to prostaglandin administration softens the cervix, increases the sensitivity to prostaglandins and thus converts the quiet pregnant uterus into an organ of spontaneous activity [8] leading to reduction in IAI, the total dose of prostaglandins required as well as the analgesia requirement $[7,9]$.

The combination of mifepristone followed by misoprostol has been found safe and effective for mid trimester termination of pregnancy in various studies $[5,10,11]$. The present study was conducted to assess efficacy of

Available online at: www.medresearch.in 34 | P a g e 
combination of Mifepristone followed by successive doses of vaginal misoprostol in comparison to use of vaginal misoprostol alone for midtrimester abortions, to observe the course of induction abortion interval, outcome of abortion using the above protocol and to study any side effects of the above regimen.

\section{Methods and Materials}

This prospective longitudinal study was done in a tertiary care teaching hospital. A total of 50 women, who presented to us for termination of pregnancy between 1328 weeks period of gestation due to various reasons were included in accordance with the inclusion criteriafrom June 2016 to October 2017.

A detailed history of the case regarding menstrual, obstetric, personal, medical with special reference to cardiovascular, respiratory, GIT, endocrinal disorder and coagulopathy was obtained. General and systemic examination of the cases was done.

They were duly explained about the procedure of medical termination of pregnancy, and a written informed consent was taken from each of the participants explaining all the risks and complications and success rate of procedure.

Women were admitted in the labour ward and baseline investigations including haemogram, blood group, liver function tests, blood sugar, urine routine examination, renal function tests and viral markers were done in all the cases.

Inclusion Criteria- All patients who were admitted in the labour ward seeking medical termination of pregnancy due to various reasons between 13-28 weeks period of gestation and

- Fulfillingall the prerequisites of the MTP Act were included in the study.

- Pre-eclampsia with impending eclampsia.

- Congenital malformations (Anomalous fetus)

- IUD

\section{Original Research Article}

\section{Exclusion criteria}

1. Women who were haemodynamically unstable at the time of presentation.

2. Women who had either taken MTP Pill from outside or self-prescribed or who came with inevitable or incomplete abortion.

3. Women with known heart disease,

4. Bronchial asthma or coagulation disorder,

5. Women on anti-coagulant or corticosteroids.

6. Haemoglobin $<8$ gm $\%$.

7. Known hypersensitivity to mifepristone or Misoprostol.

8. Women not fulfilling the pre-requisites of Indian MTP act, 1972.

After admission and checking the baseline investigations, the cases were randomly divided in two groups of 25 each. Study group received $200 \mathrm{mg}$ of mifepristone on admission. After $24 \mathrm{~h}$ in these cases $200 \mathrm{mcg}$ of misoprostol was inserted vaginally and thereafter $200 \mathrm{mcg}$ every $6 \mathrm{t} h$ until the abortion occurred or up to a maximum of 8 doses. Control group: the cases received misoprostol only in the same dose schedule. The cases were closely monitored for side effects if any, the onset of contraction, bleeding cervical dilatation each time before insertion of each misoprostol. Induction abortion interval, since the insertion of the first intravaginal tablet of misoprostol was noted down. The time of expulsion of foetus and placenta was noted. Placenta was examined to confirm its totality the process is considered failed if abortion fails to occur in $48 \mathrm{~h}$ of the insertion of the first tablet of misoprostol, incomplete if part or whole of the placenta is retained. In case of failure another method medical or surgical was tried. Rh antibody was given to all the Rh-negative cases at the end of the procedure.

Following outcomes were measured-

- Rate of complete abortion

- Induction to abortion interval

- Failure to achieve complete abortion within intended time interval and maximum intended dose of Misoprostol

All the data collected was entered in excel sheet and were analysed statistically with SPSS version 16 software. Results were calculated.

\section{Results}

Majority of the cases in both the groups were between 21 and 30 years of age. The mean age of women included in the study was 25.8 years with the range of 18 to 36 years. The majority of the women were with the parity of 2 . There were 3 women with previous caesarean scar. 34 women underwent MTP for congenital malformations like, neural tube defects like anencephaly renal malformations. In 7 women the reason for termination was IUD, 5 in view of missed abortion and 4 in view of unwanted pregnancy i.e. they had conceived during lactational amenorrhoea, $84 \%$ of the cases aborted by 9 hours in the study group against only $8 \%$ in the misoprostol alone group. 
Table 1: Age Distribution.

\section{Original Research Article}

\begin{tabular}{|c|c|c|c|}
\hline Age in Years & $<20$ & $20-30$ & $>30$ \\
\hline Case & $\mathbf{3}[6 \%]$ & $\mathbf{1 9}[38 \%]$ & $\mathbf{3}[\mathbf{6 \%}]$ \\
\hline Control & $\mathbf{1}[\mathbf{2 \%}]$ & $\mathbf{2 0}[\mathbf{4 0} \%]$ & $\mathbf{4}[\mathbf{8 \%}]$ \\
\hline Total & $\mathbf{4}[\mathbf{8 \%}]$ & $\mathbf{3 9}[\mathbf{7 8 \%}]$ & $\mathbf{7}[\mathbf{1 4 \%}]$ \\
\hline
\end{tabular}

Majority of the cases in both the groups were between 21 and 30 years of age. The mean age of women included in the study was 25.8 yrs with the range of 18 to $36 y r s$

Table 2: Parity Distribution.

\begin{tabular}{|c|c|c|c|}
\hline Parity & PRIMI & 2 & $\geq 3$ \\
\hline Case & $8[16 \%]$ & $16[32 \%]$ & $2[4 \%]$ \\
\hline Control & $12[24 \%]$ & $10[20 \%]$ & $2[4 \%]$ \\
\hline Total & $20[40 \%]$ & $26[52 \%]$ & $4[8 \%]$ \\
\hline
\end{tabular}

The majority of the women were with the parity of 2

Table 3: Indication for Termination.

\begin{tabular}{|c|c|c|c|}
\hline & $\begin{array}{c}\text { Congenital } \\
\text { malformation }\end{array}$ & Intrauterine death & Missed abortion \\
\hline Case & $20[40 \%]$ & $6[12 \%]$ & $2[4 \%]$ \\
\hline Control & $14[28 \%]$ & $5[10 \%]$ & $3[6 \%]$ \\
\hline Total & $\mathbf{3 4}[\mathbf{6 8 \%} \%$ & $\mathbf{1 1}[\mathbf{2 2} \%]$ & $\mathbf{5}[\mathbf{1 0} \%]$ \\
\hline
\end{tabular}

Table 4: Induction abortion interval.

\begin{tabular}{|c|c|c|c|}
\hline I.A.I Duration in hours & Study group & ControlGroup & Pvalue \\
\hline $0-5 \mathrm{hrs}$ & $6[24 \%]$ & 0 & $<0.001$ \\
\hline $5-10 \mathrm{hrs}$ & $23[92 \%]$ & $1[4 \%]$ & $<0.001$ \\
\hline $10-15$ & $25[100 \%]$ & $3[12 \%]$ & $<0.001$ \\
\hline Mean duration & $\sim 7 \mathrm{hrs}$ & $18-20 \mathrm{hrs}$ & $<0.001$ \\
\hline
\end{tabular}

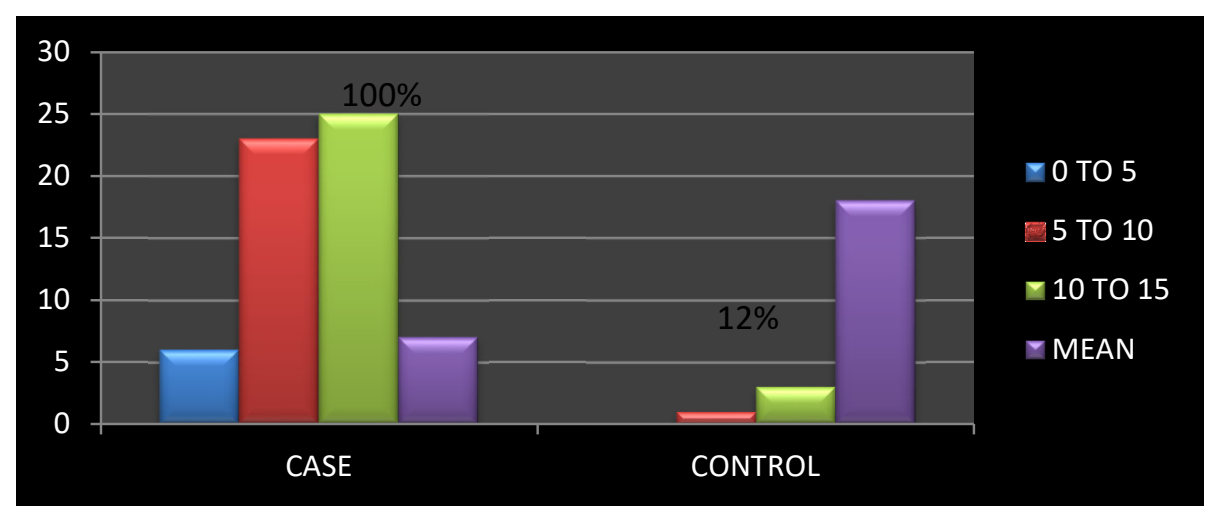

All the cases in the study group aborted within $15 \mathrm{~h}$ in the study group as against only $24 \%$ in the control group. The mean induction abortion interval was around $7 \mathrm{hrs}$ in study group as compared to 18-20 hrs in control group the abortion was complete in $100 \%$ in study group while $92 \%$ in control group, with $8 \%$ failure for which Hysterectomy was done. The mean dose of Misoprostol required was significantly less in the study group 400mcg as compared to $1000-1200 \mathrm{mcg}$ in control group, respectively. The side effects observed were mainly nausea, vomiting, fever, abdominal cramps and flushing and diarrhoea in study and control group. 


\section{Discussion}

Mid-trimester MTP is a difficult situation owing to the prolonged time required for the abortion process and associated complications. In developing countries especially, rural areas second trimester MTP is a real challenge owing to the limited resources available.

There are many studies with different dosage schedules of combination of mifepristone and Misoprostol for 2nd trimester MTP. We compared our study with other studies using a similar drug protocol of $200 \mathrm{mg}$ mifepristone followed by vaginal

Misoprostol with minor variations of subsequent dosages and route of administration of Misoprostol. Various studies have shown higher success rate and reduced induction to abortion interval and need for lesser dose of misoprostol when mifepristone is added to misoprostol $[5,9,10]$. Treatment with mifepristone softness the cervix, increases sensitivity of uterus to prostaglandins. The success rate was $100 \%$ in present study. Different studies have shown success rates varying from $73 \%-97 \%$ with combination of mifepristone followed by vaginal misoprostol $[5,6,11]$.

We have given misoprostol vaginally 24 hrs after priming with mifepristone. First dose administered was $200 \mathrm{mcg}$ followed by $200 \mathrm{mcg}$ vaginally after 4-6 hrs depending upon uterine contractions and previous history of uterine surgery. It has been seen that vaginal route of administration for misoprostol is safer and more effective than oral route with less side-effects $[11,12]$ due to better bioavailability of the drug at target site [13].

The mean total dose of misoprostol required in the present study was $400 \mathrm{mcg}$. Other studies reported in literature show dosage requirements varying from nil to $2200 \mathrm{mcg}$ $[14,15]$. The induction abortion interval was significantly shorter around $7 \mathrm{hrs}$ in study group while it was $18-20 \mathrm{hrs}$ in the misoprostol alone group $[\mathrm{p}<0.001]$ which is comparable to other studies $[7,11,12]$.

There were three patients in our study who had undergone caesarean section prior to present pregnancy. All of them had complete abortion with combination of mifepristone and Misoprostol regimen. There are various case reports showing uterine rupture in previously scarred uterus undergoing mid-trimester pregnancy termination [16,17]. But, many studies have shown safety of mifepristone \& misoprostol for mid-trimester MTP in cases of previous caesarean section $[18,19]$. The commonly observed side effects were nausea, vomiting, fever, abdominal cramp and diarrhoea.

Obsgyne Review: Journal of Obstetrics and Gynecology

\section{Conclusion}

Second trimester termination of the pregnancy using combination of mifepristone and misoprostol is a safe, non-invasive, highly cost-effective method with a high success rate and short Induction Abortion Interval.Pretreatment with mifepristone adds to the effectiveness of the misoprostol as an abortifacient. In majority of the cases surgical evacuation and its attendant complications can be avoided by using medical methods of pregnancy termination. The combination can be used in cases of previous scarred uterus under strict monitoring.

Funding: Nil, Conflict of interest: Nil

Permission from IRB: Yes

\section{References}

1. Medical Termination of Pregnancy Act, 1971

2. Drey EA, Foster DG, Jackson RA, et al. Risk factors associated with presenting for abortion in the second trimester. DOI:10.1097/01.AOG. 0000189095. 32382.d0

3. Grimes DA. The continuing need for late abortions. JAMA. 1998 Aug 26;280(8):747-50.

4. Medical methods for termination of pregnancy. Report of a WHO Scientific Group. World Health Organ Tech Rep Ser. 1997;871:i-vii, 1-110.

5. Lalitkumar S, Bygdeman M, Gemzell-Danielsson K. Mid-trimester induced abortion: a review. DOI:10.1093/ humupd/dm1049

6. Hammond C. Recent advances in second-trimester abortion: an evidence-based review. DOI:10.1016/j.ajog. 2008.11.016

7. Ashok PW, Templeton A, Wagaarachchi PT, Flett GM. Midtrimester medical termination of pregnancy: a review of 1002 consecutive cases. Contraception. 2004 Jan;69 (1): 51-8.

8. Bygdeman M, Swahn ML. Progesterone receptor blockage. Effect on uterine contractility and early pregnancy. Contraception. 1985 Jul;32(1):45-51.

9. Nagaria T, Sirmor N. Misoprostol vs mifepristone and misoprostol in second trimester termination of pregnancy. DOI:10.1007/s13224-011-0118-4

10. Hamoda H, Ashok PW, Flett GM, Templeton A. A randomized trial of mifepristone in combination with misoprostol administered sublingually or vaginally for medical abortion at 13-20 weeks gestation. DOI:10.1093/ humrep/ dei037

Available online at: www.medresearch.in 37 | P a g e 
11. Ho PC, Ngai SW, Liu KL, et al. Vaginal misoprostol compared with oral misoprostol in termination of secondtrimesterpregnancy.DOI:10.1016/S0029-7844(97)00419-5

12. Ngai SW, Tang OS and Ho PC. Randomised comparison of vaginal ( $200 \mathrm{mcg}$ every 3 hourly) and oral (400 mcg every 3 hourly) Misoprostol when combined with mifepristone in termination of second trimester pregnancy. Hum Rep 200;15:2205-8.

13. Tang OS, Chan CC, Kan AS, Ho PC. A prospective randomized comparison of sublingual and oral misoprostol when combined with mifepristone for medical abortion at $12-20$ weeks gestation. DOI:10. 1093/humrep/dei196

14. el-Refaey $\mathrm{H}$, Templeton A. Induction of abortion in the second trimester by a combination of misoprostol and mifepristone: a randomized comparison between two misoprostol regimens.Hum Reprod.1995 Feb;10(2):475-8.

\section{Original Research Article}

15. Agarwal N, Gandhi G, Batra S, Sharma R. Evaluation of mifepristone and Misoprostol for medical termination of pregnancy between 13-20 weeks of gestation. Indian Journal of Clinical practice. 2014;24(9):859-62.

16. Chen M, Shih Jc, Chiu WT, Hsieh FJ. Separation of caesarean scar during second trimester intravaginal Misoprostol abortion. ObstetGynaecol1999;94:840.

17. Berghahn L, Christensen D, Droste S. Uterine rupture during second-trimester abortion associated with misoprostol. Obstet Gynecol. 2001 Nov; 98(5 Pt 2):976-7.

18. Dickinson JE. Misoprostol for second-trimester pregnancy termination in women with a prior caesarean delivery. DOI:10.1097/01.AOG.0000151996.16422.88

19. Herabutya Y, Chanarachakul B, Punyavachira P. Induction of labor with vaginal misoprostol for second trimester termination of pregnancy in the scarred uterus. Int J Gynaecol Obstet. 2003 Dec;83(3):293-7.

\section{How to cite this article?}

Mahendra G, Vyshali. R, VijayalakshmiS. Study of Mifepristone and Misoprostol Vs Misoprostol alone in mid trimester termination of pregnancy in tertiary care hospital.Obs Rev:J obstet Gynecol 2018;4(2):34-38.doi: 10.17511/joog.2018.i02.03. 